\title{
Research on the Development of China's Rule of Law under the "Belt and Road" Strategy
}

\author{
Yunhao Cui \\ Shanxi University of Finance and Economics, Taiyuan, Shanxi, 030006, China
}

Keywords: Belt and Road; culture; cooperation mechanism; rule of law

\begin{abstract}
In light of the issue of China's legal construction of the "Belt and Road", it is required to focus on strengthening basic theoretical research, strengthen the initiative of the "Belt and Road" legal construction research, promote interdisciplinary comprehensive communication, broaden the study of legal sciences and the international perspective of communication between them, highlight the comprehensive research on the "Belt and Road" initiative, and promote academic exchanges. Legal law research should focus on the construction of China's rule of law system, and take the national governance system and governance ability as the core of modernization, and realize problem orientation to promote the development of the rule of law in China.
\end{abstract}

\section{Introduction}

The Fourth Plenary Session of the 18th CPC Central Committee carried out an important top-level design for how to comprehensively promote the rule of law. The legal law research has done a lot of research in terms of how to promote the construction of a socialist country under the rule of law, especially to build and use the impact of guidance, promotion, and guarantee under the "Belt and Road" strategy. The "Belt and Road" strategy serves as an important public product that China provides for the world's common development. The major challenges of the innovative development practices of the "Belt and Road" approach to legal research and corresponding legal exploration are to break the barriers of traditional secondary disciplines, and thus to promote interdisciplinary and even cross-cultural national communication, which will be more conducive to a lasting high-level, comprehensive mutual promotion and development in the practice and research field of law. However, the problems that need to be solved at present are numerous and complex, among which the exploration of research is also very difficult and factors that can affect the quality of legal research are a lot.

\section{Literature Review}

There are many research results related to the construction of the "Belt and Road" in China. However, the research of the rule of law is still in a state that is not rich enough. Judging from the current research on China's legal construction, Ma Tianshan (2015) believes that the "Belt and Road" strategy can bring a certain amount of intersection of China's rule of law and more countries, nations, laws and cultural traditions in a wider and longer period of time, thus needs to take up a very arduous task in a more complex environment and achieves a phased achievement. As far as the current status where legal system promotes the "Belt and Road Initiative", Bao Yuncheng (2015) believes that the laws governing the construction of the "Belt and Road" mainly include global laws, regional laws, bilateral laws and other relevant domestic laws. Yet, there are probably a lot of conflicts between these laws, whose resolution should follow the principle of enforcement of the law first, and reasonable rules need to be set based on the actual situation. As far as research related to tax law is concerned, based on the implementation of the "Belt and Road" strategy, Qi Tong (2015) argues that related infrastructure overseas needs to be able to achieve a corresponding solution to international taxation issues, and then points out that China should promote the optimization of regional taxation 
and the rule of law of the countries along the routes and create a new pattern of international taxation cooperation. While China is clearing up the corresponding tax preferential policies, tax-related support policies should also be carefully introduced, and the process of optimizing tax credits and implement corresponding tax declaration systems should be valued. As far as the research in international law is concerned, Li Ming (2016) has studied the specific issues in the 6 key fields of the "Belt and Road"- related basic principles of international law, the maritime order, international economic law, the protection of China's overseas interests, the provision of international public goods and internet law in the perspective of international law. As a result, in general, the current domestic legal profession has conducted a variety of systematic and normative research on the topics of the "Belt and Road" field, whereas there are relevantly few results related to the in-depth study of theoretical and practical issues.

\section{Legal Problems in the Construction of "Belt and Road"}

\subsection{Problems of legal conflicts}

Generally speaking, in the international community of sovereign equality, the legislative powers of most countries are mutually independent, and different social systems have affected the formulation of laws. Therefore, conflicts between laws are unavoidable. In a nutshell, the legal conflicts in the construction of the "Belt and Road" are mainly due to the following two reasons.The first is the conflict of laws arising from the issue of religious beliefs. Most of the political and economic systems in countries and regions along the "Belt and Road" have a close relation with religious beliefs. The second is a certain legal conflict addressing the differences in attitudes and standards of the rule of law. Compared with the rule of law widely recognized by Western countries, countries along the "Belt and Road" have great difference in the standards of the rule of law. Therefore, the legal conflicts caused by differences in the attitudes and standards of the rule of law are self-evident to the impediments to the construction of the "Belt and Road Initiative".

\subsection{The heavy task of judicial system reform}

Since the 18th National Party Congress, the results of the reform of the judicial system have been remarkable. However, in the process of corresponding innovation in the new era, the task of deepening the reform of the judicial system is still heavy. Judicial personnel management classification system, judicial liability system, and occupational security system of judicial personnel, etc., all need to implement trials in the reform of the judicial system toward a comprehensive development. Rationalizing the city's management and law enforcement work, determining the boundaries of responsibility, improving laws and regulations, intensifying innovation in management methods, and strengthening the law enforcement of civilization are still some issues that need to be resolved.

\subsection{Regional economic cooperation issues}

Compared with general economic issues, the "Belt and Road" construction mainly involves two levels of cooperation. The first is cooperation at the international level. The construction of the "Belt and Road" is mainly aimed at promoting the development of trade liberalization. Therefore, in the process of realizing trade liberalization, it is necessary to promote economic growth among members in the countries along the route.

It can be seen that the issue of regional economic cooperation is mainly the core issue in the construction of the "Belt and Road". This is an international cooperation issue. In this context, the economic development of the domestic regions should be coordinated and planned, to escort the entire legal environment for the rule of law and the entire region.

\subsection{Ecology and environmental protection issues}

Since the middle of the 20th century, the issue of environmental pollution has become a major 
international issue. In order to solve this problem, the international community has jointly formulated some conventions and rules. On the one hand, it highlights the seriousness of the international environmental pollution problem; on the other hand, it provides practical experience in order to strengthen the close international cooperation and the joint governance of the environment. There are increasingly severe ecological and environmental protection issues in China. These are prominent issues in the current socio-economic development.

\section{Construction of the Rule of Law Mechanism at the Macro Level}

In order to ensure the smooth progress of the construction of the "Belt and Road", it is necessary to establish a corresponding rule of law mechanism in two aspects:

\subsection{To formulate the "Belt and Road" plan and establish a mechanism for negotiation and decision coordination}

First, the "Belt and Road" needs to be clearly defined in the Action Plan, as well as the corresponding tasks, objectives, and methods and contents of cooperation. It also needs to include long-, medium-, and short-term planning and corresponding concrete implementation measures. Second, it is necessary to build a system of senior officials' meetings composed of local governments of various countries, formulate priorities for "One Belt and One Road" cooperation and areas that need to focus on priority development, and thirdly, set up relevant executive agencies to discuss and help participate in the settlement of cooperation. Problems arise. Fourth, set up relevant executive agencies to specifically discuss and help participants solve specific problems that arise during the cooperation.

\subsection{To build appropriate supervision agencies}

The implementation of the obligations of the participating parties in the corresponding agreements is specially supervised. Hence, the author believes that based on the formulation of the Action Plan and the establishment of related negotiation and decision-making coordination mechanisms, it is necessary to reduce disputes as much as possible through consultations and negotiations, etc., to conclude code of conduct that countries along the "Belt and Road" should jointly accept and observe. Specifically speaking, first, an international conference involving heads of major countries along the "Belt and Road" should be held; secondly, all parties involved in the construction of the "Belt and Road" make use of the existing legal system, thirdly, specific issues such as policies, facilities, trade and funds should be addressed and resolved involved in the construction process through agreements.

\subsection{To insist on problem-oriented research on the development of China's rule of law}

The construction of the "Belt and Road" co-constructed rule of law aiming at building a socialist legal system with Chinese characteristics and the construction of a socialist country under the rule of law comprehensively tested China's ability to comprehensively promote the rule of law. Co-constructing the "Belt and Road" legal guarantee is a comprehensive advancement of governing the country according to law. The focus of the construction of the rule of law system is the reality of China. The focus is on the need to focus on the "Belt and Road" rule of law. The "Belt and Road" legal construction and practice should be based on the socialist system with Chinese characteristics and the corresponding theory of socialist legality, focus on the system that can speed up the formation of a complete legal system, strengthen the construction of the rule of law government, and build a complete judicial supervision and guarantee system, and raise important issues such as the awareness of the rule of law in the entire society.

\section{Micro-level legal system construction}

If the macro-level rule of law mechanism of the "Belt and Road" construction is to implement the "Belt and Road" to provide macro-level guidance, it is necessary to carry out construction on a more abstract level, and then the legal construction at the micro level must be resolved around the legal 
issues in the construction of the "Belt and Road".

\subsection{To establish a mechanism to coordinate legal conflicts}

The goal of the "Belt and Road" construction is to gradually develop the "five links" (i.e., strengthen policy communication, road connectivity, smooth trade flow, currency circulation, and popular support) from point to area, from line to film, and gradually form regional cooperation among China, Central Asia, West Asia and Europe. Therefore, the author believes that it is necessary to build the adjustment mechanism of the legal conflicts in the construction of the "Belt and Road" from the principle and method levels.

\subsection{To establish a legal guarantee mechanism in regional economic cooperation}

The questions on how to build a set of effective and generally acceptable cooperation among regional economies and that we must pay attention to in the "Belt and Road" construction process are: in the first aspect, when it comes to various aspects, especially the interests of various countries and regions, in the more important aspects, it is necessary to achieve major issues between the interests of various countries and regions, and to achieve full communication and coordination throughout the entire process, to fully express the opinions and wishes in the construction of the "Belt and Road" through a reasonable mechanism; in the second aspect, a set of settlement mechanisms with Chinese characteristics and in line with China's commercial dispute resolution will be constructed to enhance China's discourse power in the resolution of international disputes. Third, in the domestic regional economic cooperation, through the establishment of the Basic Law of Regional Economic Cooperation, the legal guarantee of domestic regional economic cooperation is realized to highlight the economic superiority and vitality of the partner's region.

\subsection{To build the cooperation mechanism of the rule of law in ecological and environmental protection}

The construction of the "Belt and Road" must be accompanied by ecological and environmental issues. Therefore, in the construction of the "Belt and Road Initiative," it is also necessary to establish a legal and legal cooperation mechanism for ecological and environmental protection from both international and domestic perspectives. First, ecological and environmental protection should be used as a mechanism for common disaster prevention and control along pipelines and cross-border river basin management. Second, treaties on the ecology of the eyeliner and environmental protection should be formulated and signed. It is particularly worth noting that due to the strong influence of multinational corporations in the construction of the "Belt and Road Initiative," they should conclude relevant treaties that mandate transnational corporations to undertake ecological environmental protection obligations.

\section{Summary}

The use of the rule of law approach and the rule of law thinking to promote the building of the "Belt and Road" is an important method for implementing the "Belt and Road" strategy. The current legal problems in the construction of the "Belt and Road" are mainly those of conflict of laws, regional economic cooperation, ecological and environmental protection issues, the legal status of civil organizations participating in the "Belt and Road Initiative" and the convergence and revision of relevant domestic legislation. Under the background of the construction of the rule of law and the "Belt and Road" co-construction, the study of Chinese legal law is faced with many practical problems and potential challenges. China needs to actively promote the issue of the "Belt and Road" co-construction, but the international community is paying more attention to how China can maintain its development status. Jurists and legal experts should seize the current important opportunities, closely integrate the "Belt and Road" related legal theories, and combine relevant time, adhere to theoretical guidance, problem orientation, and practice orientation, so as to thoroughly discuss the development strategies, strategic objectives, strategies for strategic development, and strategic 
development priorities of the "Belt and Road" co-construction practice, and consequently try to make a detailed and clear explanation of the key issues in the "Belt and Road" rule of law construction to develop innovative results that have important value.

\section{References}

[1] Hu Yuting. Research on the Legal Method of Combination of Nanchong and "Belt and Road", Chinese Market, 2018(12): 173-174.

[2] Wang Haijun. Legalization of "Belt and Road" Construction: Change of Legal System in Central Asia and Regional Legal Cooperation in China, Journal of Yangzhou University (Humanities and Social Sciences), 2018, 22(02):30-40.

[3] Liu Jingdong. Prospering the "Belt and Road" Study of the Rule of Law Establishing the "Belt and Road” Legal System Theory, People's Rule of Law, 2018 (02): 7-11.

[4] Wang Xigen, Li Xiguang. The Optimization of Legal Service System from the Perspective of "Belt and Road"-Analysis Based on the Idea of Legal Value, Journal of Wuhan University (Philosophy and Social Sciences), 2018, 71(01):106-116.

[5] Yang Jinfan. The Construction of the Rule of Law Promoted by the "Belt and Road", Western Law Review, 2017(06):30-39.

[6] Liu Jingdong. Research on the Construction of "Belt and Road" Rule of Law System, Political Science and Law Forum, 2017, 35(05):125-135.

[7] Geng Zhenshan, Xu Qingqing. "Belt and Road” National Strategy Promoted by Excellent Legal Services - Focused on the "Belt and Road" Legal Services Symposium and the Sixth Standing Committee of the 5th China Behavior Law Society, People's Rule of Law, 2017 (08):52-59.

[8] Wang Gang. Legal issues and the construction of the rule of law in the construction of "Belt and Road”, Journal of Law of China, 2017, 38(02):30- 36.

[9] Wuhan Zhicheng Times Cultural Development Co., Ltd. Proceedingsof 2017 the $3^{\text {rd }}$ International Symposiumon Social Science (ISSS2017), Wuhan Zhicheng Times Cultural Development Co., Ltd:, 2017:5.

[10] Cai Shufang. The Implementation of the "Belt and Road" Strategic Concept Urgently Needs to Strengthen the Rule of Law of Local Government, Xi'an Daily, 2016-09-26(A07).

[11] Li Xiuyi. The Building of China's Local Governments' Relations in the Construction of "Belt and Road"-Based on the Perspective of Rule of Law Thinking, Journal of Chifeng College (Chinese Philosophy and Social Sciences Edition), 2016, 37(07):122-124. 